\title{
Protes Sosial Masyarakat Parean Girang, Indramayu terhadap Relokasi Peternakan Babi (1995-1996)
}

\author{
Wahyu Iryana \\ wahyu_iryana@yahoo.com \\ Mahasiswa Pascasarjana Ilmu Sejarah Program Doktoral FIB UNPAD
}

\begin{abstract}
Since 1995-1996 in Parean Girang Kandanghaur Indramayu there was accident the rejecting of the pig cattle relocation. That history actually from a wish investor to make it happen in Jakarta, but because there is no area therefore overwhelmed in West Java Governance to take in Bogor, Tanggerang, Lebak, Bekasi, and also Karawang will be taken for cattle of pig, but the regents of all countries to refuse it. Therefore a side of the governor Indramayu is welcome of making permission for the investor to open the cattle of pig relocation in their country. Therefore the cattle of pig is undertaken in Indramayu actually in Parean Girang, well this moment making reaction for public in Parean Girang where unwillingness on the decision for the governor. The purpose of this thesis is to address to present Sartono Kartodirjo, history is causality contact was start from social fluctuation where making the community disturbance and social changes. On this matter comprises many factor Values, Economy, Religius, Politic, Social-culture on Social-structure. We can said that to create a Necassery Condition and Sufficient Condition. The thesis explained a comparation of these perspectives and theories responses, as follow 1) To know how well-understood backround the arise cattle of Pig in Parean Girang Kandanghaur 2) To understanding action of refusing cattle of a pig in Paren Girang Kandanghaurfor making a pig relocation. The thesis used with history of metodolgy is method to study accident in the past to purpose making reconstruction of objective and systematic history. The methods is comparations with Heuristic, Critic, Interpretation, and Historiografy. The thesis to try express well-understood being history of refusing a Pig relocation in Parean Girang since 1995-1996. Start from moving a cattle of pig relocation process from Jakarta to Indramayu where it is making polemic and protest being various community, because of Economy, Relgious, Politic, and Sosilaculture. It is making unwillingness for community, where finished on decided latter of negation from MUI No: 08/MUI-Kec/VI/1995 its sense to object to that cattle of a pig relocation. This has led community initiatives Parean Girang village District of Kandanghaur tounder take preventive measures rejecting the relocation ofpig farms. Various ways have been made include working withthe media, Ngosor Islamic organizations, issued astatement, and the demonstrations that led to the revolution in Indramayu Regional Government on 29 April 1996.

Keywords: Refusing, Pig, Indramayu.
\end{abstract}

\section{A. Pendahuluan}

PT. Sari Kentjana Jaya Utama ingin membuka lahan perternakan babi di desa Parean Girang Kec.
Kandanghaur dengan luas tanah sekitar 500 hektar. Sebelumnya Pihak PT. Sari Kencana juga mencoba membuka usaha serupa di desa Karangsari, Karang 
Sembung, dan Karang Harum dimana ketiganya berada di daerah Bekasi. Juga di desa Cemara Jaya Kecamatan Cibuaya Karawang. Namun Masyarakat sekitar juga telah menolaknya. (Tabloid UMMAT, Edisi No 9 thn 1, 30 Oktober 1995-1996/ Jumadil Akhir 1416 H).

Usaha PT. Sari Kenjtana Jaya Utama untuk membangun peternakan babi di Desa Parean Girang ahirnya tercium juga oleh masyarakat Indramayu dan ahirnya diwacanakan secara meluas, maka soal haram halal pun menjadi sumber keributan dan menjadi isu sosial keagamaan yang cukup panas. Sejumlah tokoh masyarakat sempat memecahkan dan menetapkan pandangan hukumnya, bahwa sesuatu yang bisa menyempurnakan dan mewujudkan barang yang haram, seperti tempat untuk beternak babi, maka kegiatan dan mengizinkan tempat itu pun menjadi haram adanya. Akibatnya permasalahanpun muncul dan mencuat kepermukaan yang pada akhirnya mendorong mayarakat Indramayu khususnya daerah Kandanghaur untuk melakukan protes dan menolak diadakannya proyek peternakan babi di Desa Parean Girang. Protes tersebut merupakan bentuk penentangan atas persetujuan Bupati Indramayu yang pada waktu itu dijabat oleh H.Ope Mustofa, melalui rekomendasi untuk PT. Sari Kentjana dengan nomor SK 524.2/142/bppa/1995 perihal persetujuan usaha peternakan babi.

Alasan Bupati H. Ope Mustofa menerima kehadiran proyek peternakan babi di daerah Kandanghaur Indramayu itu adalah ingin meningkatkan taraf hidup ekonomi masyarakat Indramayu khususnya dalam bidang keterampilan beternak. Bupati menambahkan dengan adanya proyek peternakan babi ini diharapkan dapat mengoptimalkan potensi daerah Indramayu yang dipimpinnya.

Senada dengan hal itu Wagub Jabar Bidang Pemerintahan dan Kesra Pada Surat Kabar Pikiran Rakyat (PR), Edisi Kamis 11 April 1995menghimbau bahwa masyarakat Indramayu harus mendapatkan sosialisasi yang bersifat murni tanpa rekayasa harus benar-benar dari bawah, karena masyarakat Jabar adalah masyarakat agamis. Namun tidak demikian respon masyarakat Indramayu. Melalui surat protes yang merupakan hasil mufakat dan musyawarah digedung MUI Kandanghaur pada tanggal 11 Juni 1995 masyarakat Kandanghaur merasa keberatan dengan adanya proyek peternakan babi didesa Parean Girang. Apalagi sebagian besar masyarakat Kandanghaur memeluk agama Islam. Surat MUI Kandanghaur yang ditujukan langsung pada Bupati Indramayu ini dilengkapi juga dengan dalil-dalil alQur'an maupun hadits-hadits Nabi Muhammad SAW. MUI Kandanghaur berpendapat bahwa adanya proyek peternakan babi berikut pengolahannya itu selain bertentangan dengan Syariat Islam yang juga akan merusak aqidah umat Islam. Oleh karena itu MUI Kandanghaur yang pada waktu itu dijabat oleh KH. Jamali merasa terpanggil untuk mendesak semua pihak agar memperhatikan semua aspek yang nanti bakal ditimbulkan. (Surat MUI Kandanghaur No: 08/MUI/VI/1995. Tanggal 21 Juni 1995)

Seruan ketua MUI Kecamatan Kandanghaur KH. Jamali disambut baik oleh para mahasiswa Indramayu yang kuliah di luar kota seperti ungkapan Forum Silaturahmi Pelajar Mahasiswa Indamayu (Fokus Pemayu) Jogjakarta menyatakan bahwa adanya proyek peternakan babi dengan luas areal tanah 500 hektar diwilayah KandanghaurIndramayu sesungguhnya tidak akan 
mempunyai akses langsung terhadap perekonomian masyarakat Indramayu, sebaliknya kehadiran proyek itu justru akan memicu keresahan dan kekerasan mayoritas muslim di wilayah tersebut. Sentimen keberagaman akan terusik dan akan berakulminasi pada ketegangan atau konflik SARA yang bersifat horizontal. Surat protes Fokus Pemayu Jogjakarta yang ditunjukan langsung pada Bupati Indramayu dengan nomor : 05/Fokus Pemayu /V/1996.

Dukunganpun terus mengalir dari berbagai ormas Islam seperti sejumlah ormas pelajar pemuda Islam Jabar ( HMI Badko Jabar, PW pemuda Persis Jabar, DPD IMM Jabar, PKC PMII Jabar, PW PII Jabar, serta PMIB) Mereka mengatakan bahwa peternakan babi itu tidak bersahabat. Pasalnya berdasarkan analisis terhadap dampak lingkungan peternakan babi akan mencemari lingkungan sekitar, pencemaran air, tanah dan udara dapat dipastikan merupakan akibat nyata yang akan ditanggung masyarakat setempat. Dengan demikian semua peternakan babi akan menimbulkan saripati dan akar-akar yang cukup serius, hal ini di sebabkan oleh kotoran babi yang lebih jauh lagi bisa jadi bisa menimbulkan berbagai jenis bibit penyakit. Secara sosiologis, masyarakat Indramayu-Jawa Barat mayoritas penduduknya beragama Islam. Sehingga segala bentuk etika, perilaku dan usaha akan senantiasa diwarnai dengan nilai-nilai ajaran agama Islam.

Karena itu pula, berdasarkan keputusan dan masukan Ormas Pemuda Islam Jawa Barat, peternakan babi di tempat tersebut selain bisa merusak citra warga Indramayu, juga warga Jabar secara keseluruhan. Proyek peternakan babi, menurut Ormas Pelajar dan Pemuda Islam bertentangan dengan upaya pemerintah dan instansi terkait, seperti MUI (Majelis Ulama Indonesia) yang memasyarakatkan lebelisasi "halal" sebagai salah satu makanan sehat, dalam bembahasan RUU tentang pangan yang mendapat dukungan presiden Soeharto. Proyek peternakan babi, jelas suatu langkah yang merusak cita-cita dan semangat RUU pangan tersebut, tegas Ormas Pelajar-pemuda Islam Jabar. (Pikiran Rakyat. Edisi Selasa (Pon) 28 Mei 1996).

Sebagaimana yang diungkapkan oleh Hans Albert diantara aspek-aspek sosial dalam dogmatisme yang terpenting adalah tatanan institusional yang dibuat oleh kelompok dengan sistem keyakinan dogmatik menjadikan penolakan terhadap alternatif-alternatif solusi persoalan sebagai suatu kewajiban. (Hans Albert, 2014: 161).

Permasalahan peternakan babi ini telah membuat gusar banyak kalangan termasuk KH. Fuad Hasyim seorang ulama yang disegani sewilayah III Cirebon yang juga pengasuh Pondok Pesantren Buntet, beliau merasa kaget karena belum adanya tanggapan dari PEMDA Indramayu dan seolah-olah semua pihak tutup mata mengenai hal ini. Dari hasil pertemuan bersama dalam acara Forum silaturahim ulama dan pemuka Islam Indramayu tanggal 1 Oktober 1995 para ulama berharap kepada ketua DPRD Indramayu sebagai wakil Rakyat dan $H$. Bupati Ope Mustofa untuk menolak proyek peternakan babi.

Gerakan protes keagamaan dalam kontek revivalisme dan sektarianisme yang digerakkan oleh ulama Indamayu khususnya di daerah Kandanghaur ini, bisa dilihat dalam kontek hubungan kausalitas antara gerakan dengan nilai yang melandasinya. Gerakan ini tidak akan muncul tanpa adanya basis ideologi yang diperjuangkan secara bersama. Sartono Kartodirdjo (1997) mengatakan, bahwa para pemimpin 
Islam sejak abad ke -19 telah banyak menggunakan solidaritas pedesaan dalam menentang kolonialisme, karena tidak adanya pemimpin formal yang bisa diajak ke arah tujuan aspirasi kolektif dengan masyarakat di bawahnya. Solidaritas petani yang dilandasi agama misalnya, sangatlah mudah untuk digunakan sebagai modus perlawanan atau protes sosial. Emile Durkhaim melihat pula bahwa realitas seperti ini bisa disebut dan diidentikkan dengan solidaritas mekanis yaitu suatu solidaritas dalam masyarakat komunal yang berakar pada masyarakat agraris dan berpusat dan berada pada tokohtokoh kharismatiknya.

Anomi gerakan penolakan ternak babi secara sosiologis sejalan dengan pola pikir Wach yang menyebutkan adanya tiga ekspresi pengalaman keagamaan yaitu pemikiran (thought), tindakan (action), dan persekutuan (fellowship), yang pada prinsipnya gerakan ini muncul bisa dilihat dari situasi sosial pada waktu itu (Abdul Djamil, 2003:161). Hal ini sesuai dengan karakteristik masyarakat Kandanghaur baik secara sosiologi, antropolgis dan geografis maupun tipologi sosial kemasyarakatannya yang berwatak agraris. Penulis mengajukan pertanyaan penelitian sebagai berikut. Bagaimana latar belakang kebijakan munculnya usaha relokasi peternakan babi di Desa Parean Girang kecamatan Kandanghaur? Bagaimana proses dan upaya mobilisasi masa dalam aksi penolakan yang dilakukan masyarakat Desa Parean Girang Kandanghaur terhadap usaha peternakan babi? Bagaimana dampak sosial, agama dan politik dari perlawanan dan penolakan usaha relokasi peternakan babi di Kabupaten Indramayu pada tahun 1996 ? Tujuan penelitian ini tidak lain untuk memberikan Informasi peristiwa yang terjadi di wilayah Jawa Barat, memberi pengetahuan keagamaan tentang akibat negatif mengkonsumsi daging babi, sebagai Ibroh pembelajaran pemerintah dalam mengambil kebijakan agar tidak merugikan rakyat. Metode yan dipakai adalah metode penelitan sejarah (MPS), yang terdiri dari Heuristik, Kritik, Interpretasi dan Historiografi. Dari uraian tersebut diatas diatas, akhirnya penulis merasa tertarik untuk melakukan penelitian dengan judul: Protes Sosial Relokasi Peternakan Babi di Desa Parean Girang Kec.Kandanghaur-Indramayu pada tahun 1995-1996.

\section{B. Penolakan Masyarakat Desa Parean Girang Kecamatan Kandanghaur terhadap Peternakan Babi pada Tahun 1995-1996}

Aksi Protes masyarakat Desa Parean Girang Kecamatan Kandanghaur untuk menentang para investor usaha relokasi peternakan babi di daerahnya semakin memanas. Dikeluarkannya Surat Pernyataan Masyarakat Kandanghaur tertanggal 21 Desamber 1995 yang bertujuan untuk menolak relokasi peternakan babi di Desa Parean Girang Kandanghaur tersebut tidak main-main karena langsung di tujukan pada Bupati Indramayu dan Ketua DPRD Kabupaten Indramayu.

Protes masyarakat Kandanghaur tersebut sebenarnya wujud penentangan atas persetujuan Bupati Indramayu, melalui surat rekomendasi untuk PT Sari Kencana Jaya Utama, dengan nomor: 524.2/142/bppa/1995, perihal persetujuan usaha peternakan babi. Surat protes yang merupakan hasil mufakat dan musyawarah mayarakat Desa Parean Girang Kecamatan Kandanghaur langsung ditandatangani oleh para tokoh masyarakat atas nama masyarakat Kandanghaur. 
Dalam suratnya masyarakat
Desa Parean Girang

Kandanghaur menyatakan keberatan dengan adanya peternakan dan pengolahan daging babi di desanya itu, mereka beralasan bahwa sebagai Muslim harus selalu menjunjung tinggi nilai-nilai ajaran Islam dan nilai-nilai iman dan taqwa sesuai dengan hakekat pembangunan nasional yakni pembangunan manusia seutuhnya dan pembangunan masyarakat Indonesia seluruhnya, dalam artian seutuhnya adalah lahir batin, serta dalam artian seluruhnya yakni dunia dan akherat. Dalam suratnya juga, masyarakat Desa Parean Girang Kandanghaur menjelaskan jarak antara proyek peternakan babi dengan lingkungan masyarakat muslim sangat berdekatan sehingga dikhawatirkan terjadi pencemaran kotoran, yang di timbulkan oleh limbah dan polusi udara bagi penduduk yang akan mengganggu K3 (Kebersihan, Kenyamanan, Keindahan) di lingkungan masyarakat dan dapat meresahkan masyarakat.

Sebagaimana kita ketahui bahwa semboyan masyarakat Indramayu adalah: "Indramayu Mulia Asri" semboyan tersebut sebagai acuan masyarakat Desa Parean Girang Kecamatan Kandanghaur untuk melestarikan lingkungannya dan sebagai kebanggaan seluruh masyarakat Indramayu untuk di wujudkan dalam pola gerak kehidupan sehari-hari, tetapi menurut masyarakat Desa Parean Girang Kecamatan Kandanghaur dengan adanya peternakan babi akan merusak citra dari semboyan itu sendiri, karena lingkungan sekitar akan kotor baik fisik maupun non fisik, dengan kata lain wibawa dan nama baik masyarakat dan pemerintah daerah Indramayu sendiri akan tercoreng.

Dalam uraian suratnya yang terakhir masyarakat Desa Parean Girang
Kecamatan Kandanghaur sangat mendambakan lahirnya generasigenerasi penerus yang tetap menjunjung tinggi nilai-nilai ajaran Islam dan nilainilai Pancasila yang luhur itu, generasi harapan bangsa yang dapat meneruskan perjuangan pendahulunya dalam mengisi kemerdekaan dengan bekal IPTEK ( Ilmu Pengetahuan) dan IMTAQ (Iman dan Taqwa) akan tetapi dengan adanya peternakan babi di daerahnya dikhawatirkan akan meracuni keimanan generasi muda sebagai penerus perjuangan bangsa sudah terbiasa dengan hal-hal yang diharamkan oleh agama yang kemudian akan melahirkan generasi yang lemah iman dan taqwa. Hal ini jelas karena tujuan dibangunnya peternakan babi salah satunya adalah untuk menyerap tenaga kerja di wilayah Desa Parean Girang Kecamtan Kandanghaur dan sekitarnya, secara otomatis pekerjapekerjanya pun yang jelas-jelas beragama Islam karena iman dan aqidah mereka sudah goncang, dan tidak bisa membedakan hal yang batil dan yang hak apalagi jelas-jelas babi tertulis dalam AlQuran dengan tegas bahwa hukumnya haram.

Dari berbagai alasan di atas yang tertulis dalam surat penolakan masyarakat Desa Parean Girang Kecamatan Kandanghaur tetap berkenyakinan bahwa peternakan babi hanya menguntungkan seseorang (Pengusaha) dan mengorbankan kepentingan masyarakat luas ini tidak sesuai dengan hakekat dan azas pembangunan nasional. Masyarakat berharap pihak-pihak terkait, dan para pengambil kebijakan agar mengaspirasikan kehendaknya untuk menolak adanya relokasi perenakan babi di daerahnya. 


\subsection{Pandangan Para Cendikiawan terhadap Manfaat Peternakan Babi}

Sebuah usaha relokasi peternakan dan pengalengan babi akan hadir di tengah-tengah masyarakat yang mayoritas beragama muslim yaitu di Desa Parean Girang Kecamatan Kandanghaur. Sebagaian besar ulama, Cendekiawan dan tokoh masyarakat Desa Parean Girang Kecamatan Kandanghaur merasa resah dan menentang kehadiran peternakan babi tersebut yang telah direkomendasikan oleh Bupati Indramayu dengan nomor 524.2/142/bppa/1995. Akan tetapi keresahan dan kegelisahan sebagian ulama, Cendikiawan dan tokoh masyarakat itu dianggap angin lalu oleh para pengambil kebijakan di Pemda Indramayu, bahkan seolah olah para wakil rakyat pun tutup mata, tutup telinga dan tutup mulut mengabaikan semua himbauan yang pernah diberikan antara lain oleh KH. Munawir Amin Ketua MUI Indramayu, H. Aziz Ahyadi, anggota komisi B DPRD Jabar dari fraksi ABRI, KH. Fuad Hasyim Pengasuh Pondok Pesantren Buntet Cirebon, KH. Achmad Jamali Ketua MUI Kecamatan Kandanghaur.

Setelah kasus protes terhadap pendirian babi di Riau reda, kini muncul kasus serupa di Indramayu, Jawa Barat. Aksi protes para ulama Indramayu menentang kehadiran PT Sari Kentjana Jaya Utama yang akan membuka peternakan dan pengolahan daging babi di Desa Parean Girang Kecamatan Kandanghaur yang direncanakan di atas tanah seluas 500 ha, kini terus bergulir.

Protes tersebut adalah bentuk penentangan atas persetujuan Bupati Indramayu, yang pada waktu itu di jabat H.Ope Mustopa, melalui surat rekomendasi untuk PT Sari Kencana, dengan nomor 524.2/142/bppa/1995, perihal persetujuan usaha peternakan babi. Surat protes yang merupakan hasil mufakat dan musyawarah di gedung MUI Kandanghaur tertanggal 11 Juni 1995 menyatakan keberatan dengan adanya peternakan dan pengolahan daging babi di Desa Parean Girang itu dihadiri para tokoh masyarakat dan ulama seKecamatan Kandanghaur, termasuk dari Desa Parean Girang sendiri. Dalam suratnya MUI Kecamatan Kandanghaur menyatakan bahwa mayoritas masyarakat Kandanghaur beragama Islam. Oleh karena itu sebagaimana di yakini oleh orang Islam, babi adalah binatang yang diharamkan secara mutlak oleh Agama Islam sesuai dengan Surat Al Maa-Idah 3 yang artinya sebagai berikut:

...Diharamkan bagimu (memakan) bangkai, darah, daging babi, (daging hewan yang disembelih atas nama selain Allah, yang tercekik, yang dipukul, yang jatuh, yang ditanduk, dan yang diterkam binatang buas, kecuali yang sempat kamu menyembelihnya), dan (yang diharamkan bagimu) yang disembelih untuk berhala...

Surat An-Nahl 115 yang artinya sebagai berikut:

...Sesungguhnya Allah hanya
mengharamkan (memakan) bangkai, darah, daging babi, dan apa yang disembelih dengan menyebut nama selain Allah; tetapi barang siapa yang terpaksa memakannya dengan tidak menganiaya dan tidak pula melampaui batas, maka sesungguhnya Allah Maha Pengampun lagi Maha Penyayang...

Dengan demikian dapat dipahami masyarakat Desa Parean Girang Kecamatan Kandanghaur merasa keberatan dengan adanya 
peternakan babi berikut pabrik pengolahannya itu, selain bertentangan dengan syariat Islam, juga akan merusak akidah umat Islam masyarakat Desa Parean Girang yang sedang dalam pembinaan MUI Kecamatan Kandanghaur. Oleh karena itu KH. Ackmad Jamali sebagai ketua MUI Kandanghaur merasa terpanggil untuk mendesak semua pihak agar memperhatikan semua aspek yang bakal di timbulkan.

H. Azis Ahyadi, anggota Komisi B DPRD Jabar dari fraksi ABRI mengungkapkan bahwa ia pun sesungguhnya menolak kehadiran relokasi peternakan babi di Desa Parean Girang Kandanghaur tersebut dan menghimbau pada Pemda Indramayu untuk mengkaji ulang dan berkonsultasii pada para ulama serta pemuka Islam. Karena babi dengan segala aspeknya dinyatakan haram. Menurutnya Pemda jangan gegabah, harus dipikirkan dampak yang akan di temukaan nanti. Meski bisa jadi dengan adanya proyek peternakan babi menguntungkan Pemda, tetapi juga harus melihat dan menghargai umat Islam. Apa salahnya jika proyek tersebut ditolak kehadirannya, alasannya masih banyak perusahaan yang bergerak di bidang lain yang mau menanamkan investasinya di Kabupaten Indramayu. Ia juga mengharapkan agar pihak yang berwenang khususnya Pemda setempat agar bisa mendengar suara umat, jangan dianggap angin lalu, dan harus melalui musyawarah dulu dengan ulama dan tokoh masyarakat jika memang harus ada prosyek relokasi peternakan babi tersebut.

KH. Fuad Hasyim, seorang ulama dari Pondok Pesantren BuntetCirebon, juga merasa kaget dengan belum adanya tanggapan dari Pemda dan seolah semua pihak tutup mata. Dai kondang dari kota udang ini mengatakan, boleh saja di buat peternakan babi, tapi harus lihat dulu lokasinya, jangan asal bangun. Sebelum terlanjur, lebih baik batalkan saja atau didirikan di sebelah pulau yang tidak ada penghuninya. Jangan di Kandanghaur yang mayoritas Muslim. Biliau juga menyayangkan karena suara umat Islam tidak ditanggapi serius dari kalangan pengambil kebijakan, yang ditakutkan adalah adanya relokasi peternakan babi ini bisa memecah belah kerukunan umat beragama.

Dari hasil pertemuan bersama dalam acara Forum Komunikasi/Silaturahmi Ulama dan Pemuka Islam Indramayu tanggal 1 oktober 1995 juga mengharapkan kepada Bupati Indramayu dan Ketua DPRD Indramayu agar menolak proyek peternakan babi karena berdasarkan Alquran dan Hadits, babi dengan segala aspeknya adalah haram hukumnya.

MUI Jabar menghimbau agar rencana Pemda Jabar agar menyediakan lahan peternakan babi bagi Investor, ditinjau kembali. Menurut K.H. Totoh Abdul Fatah, selaku Ketua MUI Jawa Barat, kepentingan umat jangan dikalahkan oleh kepentingan bisnis semata. Totoh menilai pendapatnya bukan hanya memotret dari realita Agama Islam saja tapi juga dari kemasyarakatan dan politik. Ia juga menambahkan agar para investor melihat karekteristik masyarakat Jawa Barat yang religius. Menurut pandangannya investor yang akan membangun perernakan babi tentu tidak mempertimbangkan masalah agama.(REPUBLIKA; $\quad$ Tanggal 12 April 1996).

Pada bagian terpisah K.H. Latief Muktar, Ketua Umum Wilayah Persatuan Islam (PERSIS) Jabar, merasa kaget dengan rencana hijrahnya peternakan babi ke wilayah Jabar. Latif menegaskan menurut dalil naqli 
maupun aqli memperdagangkan babi jelas haram hukumnya. Bahkan ia menilai, sikap Pemda Indramayu yang siap menyediakn lahan, telah menyinggung perasaan umat Islam. Bahkan kalau proyek ternak babi akan di teruskan, PW Persis Jabar akan mengirimkan surat protes kepada Gubernur Jabar.

Ungkapan penyesalan juga mengalir dari Pengurus Wilayah Nahdladul Ulama (NU) Jabar. K.H. Man Muhamad Iskandar, Wakil Ketua NU Jabar. Beliau menilai masih banyak sektor lain yang akan mendatangkan pemasukan bagi kas daerah, tanpa harus bergantung pada ternak babi. Man Muhamad Iskandar juga menilai dari segi ekonomi jelas ternak babi akan menguntungkan investornya, akan tetapi keuntungan bisnis ini akan kalah dengan social cost yang harus di pikul masyarakat setempat. Dalam jangka pendek ataupun panjang keresahan masyarakat akan timbul kalau rencana ini akan terus di lakukan.

\subsection{Kepentingan Pemerintah Daerah Indramayu Membuka Peternakan Babi}

Sebenarnya adanya peternakan babi pada mulanya adalah karena Pemda DKI Jakarta mengultimatum agar peternakan babi harus sudah meninggalkan diri dari wilayah tersebut hingga batas waktu Mei 2007. Para investor ternak babi pun kemudian kelabakan dan mengincar wilayah Jawa Barat untuk dijadikan tempat baru sebagai lahan garapan . Mereka membutuhkan lahan seluas 200 hektar. Ahirnya Wagub Jabar dan Kesra yang pada waktu itu dijabat oleh $\mathrm{M}$. Sampurna berinisiatif untuk memusyawarahkannya dengan pemda Tingkat II di Jawa Barat. Kemudian diundanglah lima Bupati untuk membahas kemungkinan relokasi peternakan babi tersebut. Para Bupati yang di undang berasal dari Bogor, Tanggerang, Bekasi, Karawang, dan Lebak. Pertemuan itu juga dihadiri pejabat dari Bappeda dan Dinas Peternakan. (Muhamad Ryaas Rasyid, 2007: 100-103)

Dalam penjelasannya kepada Wartawan Wagub Jabar Bidang Pemerintahan dan kesra M. Sampurna, tanggal 11 April 1995 menjelaskan Menurutnya sudah ada lima pengusaha yang mengajukan ke Pemda Jabar. Sehingga 200 hektar itu akan di garap bersama oleh para investor tersebut. Izin lokasi yang diberikan kepada mereka bisa mencapai 30 tahun. Menurutnya semua pihak harus berpikir kedepan dan luas. "Sebagian penduduk dan turis membutuhkan daging babi. Kalau tidak disediakan nanti mengimpor. Sayang devisanya selama ini diperoleh daerah Batam," Untuk kebutuhan Jabar, menurutnya, sebagian devisa dipenuhi oleh peternakan babi kecil-kecilan di sekitar Jabar. Sehingga jika Jabar bisa menyediakan peternakan babi maka bisa jadi nanti bisa mengekspor. Sehingga klimaknya bagi Pemda Jabar adanya peternakan babi berarti akan menambahkan pendapatan daerah. Income yang akan didapat sangat besar, dari PBB, Pajak izin usaha, dan tenaga kerja bisa mencapai hingga 2,1 miliar pertahun.

Dalam pertemuan lima Bupati dengan Wagub Jabar, Bupati lima daerah itu secara prinsip menolak kehadiran peternakn babi tersebut di wilayah mereka masing-masing. Penolakan tersebut bukan merupakan faktor teknis tapi non teknis. Para Bupati tidak mau ambil resiko, karena 96 persen penduduk Jawa Barat beragama Islam. Tetapi Wagub Kesra menginformasikan bahwa Bupati Indramayu Ope Mustopa siap menerima kehadiran peternakan itu. 
Kekhasan

masyarakat

Indramayu yang terkenal dengan masyarakat pesisir, dengan kebudayaan yang dapat dikatakan bersifat adiktif pada akhirnya memunculkan perubahan-perubahan dalam bidang ekonomi dan kesempatan dalam bidang sosial yang terwujud dalam proses adaptasi dengan masyarakat sekitarnya. Tak dapat dipungkiri bahwa Indramayu merupakan daerah garis pantura yang memiliki sumber daya alam yang melimpah ruah, baik sektor pertanian, kelautan, sector migas dan yang lainnya. Tetapi pada dasarnya Pembangunan bukan semata-mata aksi sosial untuk sekedar memenuhi kebutuhan hidup bermasyarakat, berbangsa bernegara. Lebih jauh dari itu pembangunan merupakan implementasi dari tugas-tugas kekholifahan di muka bumi. Pembangunan itu juga merupakan refleksi historis dan cultural juga sosial terkait dengan cita-cita perjuangan. Oleh karena itu usaha pembangunan dalam tatanan praktisnya harus sarat dengan nilai-nilai kemanusiaan yang bersifat universal. Karena bagaimanapun juga melaksanakan pembangunan merupakan pembuatan yang luhur, agung dan suci.

Pembangunan yang telah dirancang sedemikian rupa telah dihebohkan dengan adanya relokasi peternakan babi di desa Parean Girang Kecamatan Kandanghaur. Diatas areal tanah seluas 500 hektar. Hal ini sesuai dengan SK Bupati bernomor: 524:/142/Bapp/1995 tertanggal 19 Januari 1995.

\subsection{Sikap Aparat Pemerintahan Desa Parean Girang Kecamatan Kecamatan Kandanghaur terhadap SK Bupati NO: 524.2/142/bapp/1995}

Berdasarkan peraturan pemerintah nomor 8 Tahun 1995 upaya pembenhan otonomi melalui prakarsa pemerintah pusat untuk menyerahkan urusan-urusan yang selama ini telah di jalankan di pemerintahan Tingkat II oleh aparat pusat (instansi vertikaldepartemen teknis) dan aparat pemerintahan daerah Tingkat I. Dalam implementasi di gunakan strategi otonomi birokrasi dengan teknik percontohan. Tujuan utama yang hendak di capai adalah untuk mematangkan kondisi transisi menuju terwujudnya otonomi yang nyata, serasi, dinamis dan bertanggung jawab dengan titik berat pada Daerah Tingkat II.

Adanya Sk Bupati Nomor: 524:/142/Bapp/1995 tertanggal 19 Januari 1995 tentang relokasi peternakan babi di daerahnya, merupakan bentuk konkrit adanya kebijakan otonomi daerah atas pusat. Walaupun sudah dirancang sedemikian rupa kebijakan pemerintahan daerah Indramayu tentang relokasi petrenakan babi di Desa Parean Girang Kecamatan Kandanghaur tidak disepakati oleh masyarakat setempat.

Para aparat desa dan tokoh masyarakat melakukakan pertemuan untuk memusyawarahkan tentang kebijakan pemerintah daerah Kabupaten Indramayu dalam hal relokasi peternakan babi pada tanggal 11 Juni 1995. Dalam pertemuan itu muncul kesepakatan bahwa masyarakat Desa Parean Girang Kecamatan Kandanghaur menolak adanya relokasi peternakan babi tersebut. Melalui Surat MUI Kandanghaur Nomor 08/MUIKec/VI/1995 dan Surat Pernyataan Masyarakat Desa Parean GirangKecamatan Kandanghaur, tanggal 21 Desamber 1995 bahwa masyarakat desa beserta aparatur desa Parean Girang menolak adanya relokasi peternakan babi di daerahnya. 


\subsection{Beberapa Tindakan Preventif yang Dilakukan Masyarakat Desa Parean Girang Kecamatan Kandanghaur terhadap Usaha Peternakan Babi di Desa Parean Girang}

Masyarakat Desa Parean Girang Kecamatan Kandanghaur, secara fisik geografis terletak di wilayah desa yang tergolong terpencil. Terjauhkan dari jangkauan gerakan politik, tetapi akibat yang ditimbulkannya, ketika di daerah ini terjadi pelanggaran terhadap hak-hak masyarakatnya, maka bangkitlah kesadaran politik para ulama desa peserta para pemudanya. Mereka sangat kompak dan hidup bergotong-royong, ini terjadi ketika vonis relokasi peternakan babi yang akan dilakukan di Desa Parean Girang Kecamatan Kandanghaur, maka bangkitlah kesadaran kolektif para Ulama Desa beserta aparat desa dalam satu komando. Wujud gerakannya dalam tindakan prepentif melawan hegemoni pemerintahan daerah Kabupaten Indramayu, menuntut dibatalkannya relokasi peternakan babi. Setelah bermusyawarah dengan seluruh elemen masyarakat Desa Parean Girang Kecamatan Kandanghaur mengenai relokasi peternakan babi di daerahnya. Dibantu oleh para mahasiswa, mereka melakukan tindakan-tindakan preventifentif terhadap kebijakan pemerintah Indramayu mengenai relokasi peternakan babi.

Gerakan ini dibangkitkan oleh

K.H. Achmad Jamali, seorang ulama dari Desa Karang Sinom Kandanghaur untuk melakukan pendekatan kultural dengan masyarakat Desa Parean Girang. Yang kebetulan pada saat itu ia menjabat sebagai Ketua MUI Kecamatan Kandanghaur, karena itu sebagai seorang muslim beliau juga memiliki tanggung jawab moril secara kelembagaan dan pribadi untuk membantu masyarakat Desa Parean Girang dalam hal penolakan peternakan babi. Pada tanggal 11 Juni 1995 masyarakat Desa Parean Girang dikumpulkan di Gedung MUI Kandanghaur untuk membahas masalah perenakan babi, dalam musyawarah yang dihadiri oleh seluruh elemen masyarakat itu akhirnya menghasilkan kesepakatan bahwa adanya relokasi peternakan babi di Desa Parean Girang Kecamatan Kandanghaur harus ditolak, karena berakibat fatal dan meresahkan masyarakat, maka melalaui Surat MUI Kandanghaur Nomor 08/MUI$\mathrm{Kec} / \mathrm{VI} / 1995$. dan pada tanggal 21 Desember 1995 masyarakat Desa Parean Girang melakukan musyawarah di tingkat Kecamatan, hasil musyawarah itu bersepakat bahwa masyarakat Desa Parean Girang Kecamatan Kandanghaur harus mengeluarkan surat penegasan untuk menolak relokasi peternakan babi.

Informasi adanya relokasi peternakan babi di Desa Parean Girang Kecamatan Kandanghaur itu tercium oleh para mahasiswa Indramayu yang sedang studi di luar kota, seperti Di Yogyakarta, Bandung, Jakarta. Para mahasiswa yang telah matang dalam birokrasi administrasi organisasi, dengan cepat melakukan tukar-menukar Informasi dan jaringan keseluruh mahasiswa In dramayu yang sedang studi di luar daerah. Gerakan mahasiswa ini dikomandoi oleh Fokus Pemayu Yogyakarta dan FSPMI Bandung. Mahasiswa juga mencoba mengaspirasikan keinginan masyarakat Desa Parean Girang Kecamatan Kandanghaur Melalui pendekatan birokrasi Kepada MUI Kabupaten Indramayu dan melayangkan surat Kepada ICMI ORWIL Jabar. Mahasiswa juga melakukan pendampingan kepada masyarakat Desa Parean Girang untuk melakukan 
audiensi dengan para wakil rakyat di gedung DPRD Indramayu khususnya di Komisi E. Mengeluarkan pernyataan sikap, menginformasikan kepada media dan jalan terakhir dengan demonstrasi besar-besaran.

\subsection{Berbagai Aksi Penolakan Peternakan babi yang dilakukan Masyarakat Parean Girang Kecamatan Kandanghaur}

Diikeluarkannya surat

Rekomendasi SK Bupati NO: 524.2/142/bapp/1995.Tertanggal 19 Januari 1995 tentang izin peternakan babi di Parean Girang Kandanghaur, memancing banyak tindakan-tindakan seperti berikut:

1. Pernyataan Sikap

Langkah awal yang di tempuh para mahasiswa yang tergabung dalam Forum Komunikasi Pelajar dan Mahasiswa Indramayu ( FOKUS PEMAYU) adalah membentuk tim investigasi, yang bertugas melakukan pengumpulan data yang kemudian menjadi bahan acuan untuk melakukan gerakan penolakan terhadap relokasi peternak babi.

Setelah mendapatkan surat dari tim investigasinya Tohadi bersama anggota FOKUS PEMAYU, langsung melakuan briefing mendadak untuk merumuskan langkah apa saja yang akan dilakukan selanjutnya. Setelah melakukan pengumpulan data dari berbagai sumber akhirnya pada tanggal 05 Mei 1996, FOKUS PEMAYU menyebarkan surat informasi yang di tujukan kepada seluruh keluarga besar Santri, Pelajar, Mahasiswa dan masyarakat Indramayu di seluruh Indonesia yang bertujuan untuk memobilisasi massa, dan jaringan informasi untuk membulatkan tekad dan menumbuhkan semangat persaudaraan di antara masyarakat Indramayu guna menyatukan satu visi menolak adanya relokasi peternakan babi di Desa Parean Girang Kecamatan Kandanghaur Indramayu.

Fokus Pemayu juga

mengirimkan surat kepada MUI Kandanghaur sebagai bahan evaluasi untuk pertukaran informasi dan kerjasama. Surat dari Fokus Pemayu ditanggapi positif oleh Ketua MUI Kandanghaur A. Jamali. Dalam surat balasannya tertanggal 10 pebruari 1996 MUI Kandangahaur menyatakan pihaknya menyambut baik dengan kerja sama ini dan menghimbau kepada Fokus Pemayu agar kawan-kawannya sesama kantong gerakan organisasi yang ada di Bandung dan Jakarta agar ikut memperjuangkan aspirasi masyarakat Desa parean Girang Kecamatan Kandanghaur.

Surat Fokus Pemayu yang ditujukan kepada DPRD Indramayu itu di tanggapi serius oleh para wakil rakyat, dengan mengundang Kantong gerakan Mahasiswa Indramayu khususnya FOKUS PEMAYU Yogyakarta dan FSPMI Bandung, untuk melakuan Public Hearing, pada hari Kamis, 25 April 1996. Dalam dialog terbuka dengan utusan mahasiswa itu, walaupun sebelumnya terjadi debat dan ketegangan dan belum di temukan kesepakatan, tetapi DPRD Kabupaten Indramyu berjanji untuk menyalurkan aspirasinya ke pimpinan daerah Indramayu

Fokus Pemayu juga mengirim Pernyatan sikapnya kepada MUI Kabupaten Indramayu karena dianggap belum adanya kesepakatan dan ketegasan sikap di kalangan Ulama Indramayu tentang usaha peternakan babi di desa Parean Girang Kecamatan Kandanghaur. Fokus Pemayu menganggap bahwa figur ulama merupakan petunjuk umat yang sedang kebingungan di tengah masyarakat yang sedang mencari cahaya terang, jangan 
sampai malah membingungkan masyarakat karena tidak tyegas dalam menyikapi maslah halal haram peternakan babi di Desa Kandanghaur Indramayu.

Seolah tak mau kalah Forum Solidaritas Pemuda dan Mahasiswa Indramayu (FSPMI) Bandung pun, melakukan permohonan Publik Hearing sekaligus pernyataan sikap melalui surat Istimewanya yang di tujukan pada ICMI ORWIL Jawa Barat tertanggal 10 Juli 1996, FSPMI Bandung mempertanyakan tentang kesatuan suara dan jalur koordinasi antara ICMI ORWIL Jabar dengan ICMI Orsat Indramayu yang sepakat adanya relokasi ternak babi. Sebelumnya FSPMI Bandung telah mengadakan penyelidikan dan pencarian data langsung di daerah lokasi peternakan babi yaitu di Desa Parean Girang Kecamatan Kandanghaur. Hasilnya telah dibahas dalam rapat Forum pada tanggal 21 April 1996.

FSPMI pun telah melakukan audiensi dengan pihak Dewan Perwakilan Rakyat Tingkat II Indramayu yang diwakili oleh Komisi E di Gedung DPRD Indramayu, walaupun usahanya belum membuahkan hasil yang maksimal. Cita-cita FSMPI Bandung untuk membersihkan nama baik darah Indramayu umumnya dan Desa Parean Girang Kecamatan Kandanghaur khususnya, mereka tidak mau nama Kandanghaur akan berganti nama dengan kandang babi. Usaha FSPMI Bandung untuk melakukan penolakan peternakan babi tidak mainmain. Mereka menyakini semua usahanya akan menemukan titik terang. Untuk itu FSMPI Bandung juga meminta dukungan dari aparat desa dan para pemuda setempat untuk mengisi surat pernyataan sikap tentang relokasi peternakn babi tersebut. Isinya baik berupa kekesalan, kekecewaan, saran- saran, dan lain-lain. FSPMI juga mengancam apabila pihak Pemerintahan Indramayu masih kukuh mempertahankan kemauannya untuk melakukan relokasi peternakan babi di Desa Parean Girang Kecamatan Kandanghaur. Mereka akan Demonstrasi besar-besaran. Ancaman ini memang benar adanya, setelah meminta tanda tangan kesemua Mahasiswa, pemuda dan masyarakat, mereka juga menggalang dana untuk aksinya itu.

2. Demonstrasi

Setelah melakukan rapat intern dari semua gerakan mahasiswa Yogyakarta ( Fokus Pemayu), Bandung (FSPMI), pemuda dan masyarakat Parean Girang Kandanghaur bersepakat untuk melakukan Demonstrasi di gedung DPRD Indramayu. Tepat tanggal 29 April 1996, tercatat 47 gabungan mahasiswa, 17 donatur, di tambah satu truk masyarakat desa Parean Girang Kecamatan Kandanghaur berkumpul di Terminal otobus Indramayu sebagai transit sebelum menuju kantor DPRD Indramayu. Semua perangkat aksi dari mulai megaphone, tali rapiah, dan lain-lain sudah di siapkan. Dalam tulisantulisannya dan spanduk yang di pampangnya, mereka menuliskan kami masyarakat Parean Girang Kecamatan Kandanghaur tidak mau menjadi generasi babi, dan kami menolak relokasi peternakan babi Peternakan babi mereka mengatasnamakan SOMASI (Solidaritas Mahasiswa dan Masyarakat Indramayu). Para Demonstran juga menuntut apabila aspirasinya tidak didengar oleh Bupati dan Pengambil Kebijakan di Indramayu maka mereka menuntut $\mathrm{H}$. Ope Mustofa untuk mundur darei jabatannya sebagai Bupati.Tepat jam 08.30 WIB mereka melakukan aksi demonstrasi ke gedung DPRD Indramayu. 
Menurut Haryanto Harhara dan Iin Rohimin demonstrasi adalah langkah terakhir ketika lobi dan audiensi menemukan jalan buntu. Aksi demontrasi yang dilakukan oleh seluruh elemen masyarakat untuk menolak peternakan babi itu, "merupakan aksi terbesar yang ada di Indramayu."menurut Sakum, yang sehari-hari mengayuh becanya di sepanjang terminal otobis Indramayu, juga mengatakan bahwa"arak-arakan demonstrasi itu telah memacetkan seluruh rute perjalanan menuju jalan Indramayu kota."

\subsection{Langkah-langkah yang Dilakukan Pemerintahan Kabupaten Indramayu dalam Merespon Aksi Penolakan babi}

Protes yang semula dianggap angin lalu oleh kalangan pengambil kebijakan di Pemda Indramayu mengenai relokasi peternakan babi di desa Parean Girang Kecamatan Kandanghaur akhirnya berbuntut panjang. Usaha Bupati Indramayu untuk mengumpulkan para alim-ulama pada tanggal 18 April 1996 di Gedung Serba guna Kopri dalam upaya membendung protes masyarakat dikalangan para tokoh agama menjadi sia-sia. Dalam pertemuan itu Bupati meminta para ulama Indramayu untuk mendukung adanya relokasi peternakan babi, agar mensosialisasikan kepada masyarakat luas bahwa peternakan babi dalam Islam sebenarnya di bolehkan. Bupati juga melakukan sosialisasi kepada para birokrasi dan staf jajarannya di Pemda dan tingkat Kecamatan betapa pentingnya peningkatan Ekonomi masyarakat Indramayu, Bupati berharap dengan adanya usaha relokasi peternakan babi ini adalah aset yang bisa mendongkrak pendapatan Dearah Indramayu. Namun apa yang terjadi, setelah bertubi-tibi protes yang dilakukan masyarakat Desa Parean
Girang Kandanghaur ahirnya Pemda Indramayu geram juga. Lobi-lobi politik dan tawar-menawar hargapun akhirnya kandas di tengah jalan. (Pikiran Rakyat, edisi Jum'at (WAGE) 19 April 1996: 4). Untuk melahirkan suatu keputusan politik yang menentukan denyut nadi pemerintahan Indramayu ini, bupati Indramayu baru memberikan pernyataannya setelah adanya penekanan dari berbagai elemen masyarakat dan ormas-ormas Islam di tingkat Jawa Barat, dan aksi demonstrasi yang terus-menerus disorot oleh media massa. Aksi Demonstrasi terbesar (tanggal 29 April 1996) yang merupakan gabungan dari mahasiswa dan masyarakat yang menolak relokasi peternakan babi di Desa Parean Girang Kecamatan Kandanghaur membuat gentar Bupati H. Ope Mustopa, karena takut keinginannya untuk membuka relokasi peternakan babi di Desa Parean Girang Kecamatan Kandanghaur akan jadi bumerang terhadap kedudukannya sebagai Bupati di Indramayu dan juga lawan-lawan politiknya yang selalu merongrong kedudukannya $\mathrm{H}$. Ope Mustopa sebagai Bupati. Beliau juga mengeluarkan SK sebagai intruksi membatalkan relokasi peternakan babi karena kedudukannya sebagai Bupati terancam.

\section{KESIMPULAN}

Penulis mencoba menyimpulkan hasil penelitian, yaitu:

1. Pada periode 1995-1996, di Desa Parean Girang Kecamatan Kandanghaur Kabupaten Indramayu telah terjadi peristiwa penolakan peternakan babi. Peristiwa tersebut muncul berawal dari keinginan para investor yang bermaksud membuka peternakan babi di Jakarta, namun tidak mendapat respon dari PEMDA DKI Jakarta yang tidak memiliki lahan 
untuk peternakan babi. Oleh karena sikap pemerintah Indramayu yang memberikan izin kepada para investor untuk membuka relokasi peternakan babi maka peternakan babipun dipindahkan ke daerah Indramayu, keadaan ini telah menimbulkan reaksi dalam bentuk penolakan masyarakat Desa Parean Girang Kecamatan Kandanghaur Kabupaten Indramayu yang keberatan daerahnya dijadikan relokasi peternakan babi. Hal ini memicu kalangan para ulama, cendikiawan, dan para tokoh masyarakat memberikan tentang haram halam peternakan babi. Akibatnya masyarakat menjadi resah, dan melakukan penolakan terhadap relokasi peternakan babi. Alasan logis mengapa masyarakat Desa Parean Girang menolak adanya relokasi peternakan babi di daerahnya adalah dari segi Agama, mereka menganggap bahwa adanya relokasi perenakan babi merupakan penghinaan kepada masyarakat Desa Parean Girang karena masyarakatnya kebanyakan beragama Islam. Mereka ingin selalu menjujunjung tinggi nilainilai ajaran Islam dan nilai-nilai Pancasila.

2. Masyarakat Parean Girang melakukan tindakan-tindakan preventif. Penolakan peternakan babi dimulai dari membuka jaringan informasi seluruh masyarakat seIndramayu yang ada di luar daerah dan lokal. Kemudian melakukan pendekatan prepentif kepada para pengambil keputususan, membuat pernyataan sikap, melakukan dialog dengan para wakil rakyat dan permohonan bantuan kelembagaan kepada ICMI, MUI dan ormas-ormas Islam lainnya. Dan melakukan Aksi
Demonstrasi sebagai langkah terahir ketika proses hukum dan dialog tidak dapat di selesaikan. Hal ini berdampak pada perpolitikan politik di Indramayu, karena selalu menjadi soroton media masa dan takut kedoknya terbuka akhirnya Bupati Indramayu Ope Mustofa membatalkan relokasi peternakan babi tersebut. Disinilah keunikannya bahwasannya perubahan tidak harus dilakukan dengan pertumpahan darah tetapi melalui pendekatan kooperasi pun bisa terwujud.

\section{DAFTAR PUSTAKA}

\section{BUKU-BUKU}

Al-Qur'an dan Terjemahnya Jakarta: Departemen Agama RI, 1989.

AAK, (1988) Pedoman Lengkap Beternak Babi, Yogyakarta: Kanisisus

Abdul Djamil, (2003) Perlawanan Kiai Desa KH. Ahmad Rifa'I Kalisalak, Yogyakarta:LKIS,

Ahmad Mansyur Suryanegara, Menemukan Sejarah : Wacana pergerakan Islam di Indonesia, Penerbit: Mizan, Bandung

Ahmad Mansur Suryanegara, (1995) PETA: Pemberontakan di Cileinca Pengalengan Bandung Selatan, Jakarta:Yayasan Wira Patria Mandiri.

Aqib Sumanto, (1995) Politik Islam Hindia Belanda, Jakarta: LP3ES.

Burger dan Prajudi, (1986) Sejarah Ekonomis Sosiologis Masyarakat Indonesia, Jakarta:Pradnja Paramita.

Fuad Hasan, (1989) Renungan Budaya, Jakarta: Balai Pustaka. 
Franz Magis Suseno, (2003) Pemikiran Marx; Dari Sosialis Utopis ke Perselisihan Revisionalisme, Jakarta : Gramedia Pustaka Utama.

Hans Albert,(2004) Risalah Pemikiran Kritis, Yogyakarta.: Pustaka Pelajar.

Louis Gottsalk, (1995) Mengerti Sejarah, terjemah Nugroho Notosusano,Jakarta: UI Press.

Muh. Ryaas Rasyid, (1997) Kajian Awal Birokrasi Pemerintahan Dan Politik Ore Baru, Jakarta: masyarakat Ilmu Pengetahuan Indonesia MIPI

Musa Kazhim, (1996) Мепији Indonesia Baru; Menggugat Reformasi Total, Bandung: Pustaka Hidayah.

Muh Daud Ali dan Habibah Daud, (1985) lembaga-lembaga Islam di Indoinesia, Jakarta: PT. Raja Grafindo Prasada.

Munafrizal Manan, (2003) Gerakan rakyat Melawan Elite, Yogyakarta: Resist Book.

Peter Burke, (2003) Sejarah dan Teori Sosial, Jakarta:Yayasan Obor Indonesia.

Sindu Galba, (2003) Budaya Tradisional Pada Masyarakjat Indramayu, Bandung: Balai Kajian Sejarah dan Nilai Tradisional

Zamaksari Dhofier, (1982) Tradisi Pesantren, Jakartat: LP3ES

Zainuddin Maliki, (2003) Agama Priyayi, Yogyakarta: Pustaka Marwa.
Protes Sosial Masyarakat Parean Girang, Indramayu terhadap Relokasi Peternakan Babi (1995-1996)

\section{DOKUMEN DAN ARSIP}

Pernyataan Sikap (FSPMI) Bandung, tertanggal 19 April 1996

Setaitment (FSPMI) Bandung, Perihal proyek peternakan babi di Desa parean girang Kandanghaur

Pernyataan Sikap Fokus Pemayu,Nomor Surat 05/Fokus Pemayu/ V/1996

Surat Penolakan Proyek Peternakan Babi Oleh MUI Kandanghaur No: 08/Mui-Kec/VI/1995, Tertanggal 21 Juni 1995

Surat MUI Kandanghaur pada Ketua FOKUS, Tertanggal 10 pebruari 1996.

Manuskrip Surat Tulis Tangan Anggota FOKUS PEMAYU Yogyakarta

\section{SURAT KABAR}

Tabloid Dwi Mingguan, edisi Jumat Kedua Desember 1995.

Tabloid UMMAT, Nomor. 9 Tahun 1, 30 Oktober 1995

Tabloid Forum Keadilan, nomor 17. Tahun IV, 4 Desember 1995

Surat Kabar REPUBLIKA, Tanggal 12 April 1996

Surat Kabar Pikiran Rakyat, edisi Jum'at (WAGE) 19 April 1996

Surat Kabar Pikiran Rakyat, edisi Selasa (Pon) 28 Mei 1996

Surat Kabar Pikiran Rakyat, edisi Cirebon, Sabtu 2 Maret 1996

Surat Kabar Suara Republika via Internet, Minggu, 12 Mei 1996

Surat Kabar Target, Nomor: 008/Tahun ke-1, 2-8 Juli 1996. 
IJurnal al-Tsaqafa Volume 13, No. 01, Januari 2016

Halaman sengaja untuk dikosongkan 